\title{
Risk Factors for Severe Forms of COVID-19 A Second Level Moroccan Hospital Experience
}

\author{
Rachid Taoufiq ${ }^{13}$, Meryem Essabbani ${ }^{23}$, Mouhib Nour Elhouda ${ }^{23}$, Samira Mokahli ${ }^{34}$, \\ Sara Bougar ${ }^{5}$, Nour Elhouda Oubejja 67
}

\author{
${ }^{1}$ Department of thoracic surgery, Al Farabi hospital, Oujda, Morocco. \\ ${ }^{2}$ Department of infectious diseases; Al Farabi hospital, Oujda, Morocco. \\ ${ }^{3}$ Member of prefectural committee of covid-19., Oujda, Morocco \\ ${ }^{4}$ Department of respiratory medicine, Al Farabi hospital, Oujda, Morocco. \\ ${ }^{5}$ Department of hemovigilance and immunology, Children's Hospital, Rabat, Morocco. \\ ${ }^{6}$ Laboratory of Biostatistics, Clinical Research and Epidemiology (LBRCE), Faculty of Medicine and Pharmacy of Rabat, Morocco. \\ ${ }^{7}$ Laboratory of Biology and Health, Faculty of Sciences, Ibn Tofail University, Kénitra, Morocco
}

\begin{abstract}
The new coronavirus (2019-nCoV) has caused the death of more than 1.68 million patients worldwide, including 6,909 deaths registered in Morocco until 12/20/2020. The main objective of this study is to investigate epidemiological, clinical, and paraclinical factors predicting progression to the severity in order to identify patients at risk and adopt strategies for individualized management.

We conduct this observational, descriptive, and analytical study from 01/09/2020 to 25/12/2020, at AL FARABI regional hospital in Oujda. 567 patients were eligible for our study out of 2000 patients who were admitted since our first case on April 2020. Our sample was divided into two groups based on pulse oxygen saturation on admission. We identified 294 as a Severe/Critical case and 273 as a Mild/Moderate form on admission. The mean age was significantly higher in the severe group $(63.28 \pm 12.4$ vs $55.13 \pm 17.2)$. The sex ratio $\mathrm{M} / \mathrm{F}$ was 0.87 . Compared with non-severe cases, severe cases exhibited more comorbidities, including diabetes (60.4\% vs 39.6\%; P 0.003), and hypertension (63.6\% vs 26.4\%; P 0.002). Several biological parameters were associated with disease severity in univariate analysis, the most important being lymphopenia, elevated Creactive protein, and ferritin levels. lymphopenia (OR 3.76; 95\% CI, 4.25-9.23), elevated C-reactive protein (OR, 5.7; 95\% CI, 3.84-8.48) ferritin levels (OR, 3.6; 95\% CI, 1.64-7.89) were significantly associated with severe cases of COVID-19. Mortality is $2.9 \%$ for all of our patients; it increases to $4.5 \%$ if we consider severe cases only. Identification and evaluation of epidemiological, clinical, and paraclinical parameters are important to identify patients at high risk of SARS-COV2 severity to guide treatment.
\end{abstract}

Keywords: COVID-19; Severe forms; Second level hospital, Moroccan Experience.

Corresponding author: Dr. Rachid Taoufiq, Al Farabi Hospital, Oujda, Morocco. E-mail: drtaoufiq@gmail.com

\section{Copyright (C) 2021 Taoufiq Rachid et al.}

This is an open access article distributed under the Creative Commons Attribution 4.0 International, which permits unrestricted use, distribution, and reproduction in any medium, provided the original work is properly cited.

\section{INTRODUCTION}

The coronavirus of 2019 (COVID-19), caused by a novel coronavirus (2019-nCOV), is a new form of respiratory disorder designated by the International Committee on Taxonomy of Viruses (ICTV) as severe acute respiratory syndrome coronavirus 2 (SARS-CoV-2) (1-2). This virus was likely transmitted to humans by pangolin at a seafood market in Wuhan, Hubei Province, China, in December
2019 (3). The lack of knowledge about the severity of the disease in the early stages of COVID-19, combined with the high transmissibility of the virus, has led to a dramatic increase in the number of patients and relatively high mortality worldwide. This calls for a better understanding of the various factors associated with this disease and in particular its severe forms.

The aim of this study is to investigate the epidemic-clinical and paraclinical severity factors of COVID-19 in order to 
find a simple tool for the rapid identification of potential critical patients. These factors should alert us to adapt the management of our patients. The second target, is to identify the characteristics of this African population, which has long been considered less exposed to this disease than the rest of the world's population (4).

\section{METHODS}

Data collection, and study design : This retrospective, single-center study, were conducted between 01/09/2020 and 25/12/2020 and thus included all hospitalized patients with clinical symptoms ranging from minor to severe forms. Data collection was based on patient and hospital records. Data for which there were few records and those that were not archived were excluded from the study. Epidemiological data such as age, sex and comorbidities were recorded, as well as duration of symptom course and length of hospital stay. The study also studied biological and radiological parameters and the evolution of patients. The sample is divided into two groups according to arterial pulse oxygen saturation at admission; saturation $<90 \%$ defined Severe/Critical group and saturation $\geq 90 \%$ Mild/Moderate group. We considered this saturation threshold to be close to the definition of the Chinese National Public Health Commission (5), which proposed the following criteria to define severe to critical patients: respiratory rate $>30 / \mathrm{min}$, pulse oxygen saturation $(\mathrm{SpO} 2$ ) $\leq 93 \%, \mathrm{PaO} 2 / \mathrm{FiO} 2 \leq 300 \mathrm{mmHg}$, respiratory failure and need for mechanical ventilation, signs of shock, organ failure requiring intensive care; as the study interest patients not requiring immediate assessment on the intensive care unit; these parameters were not all present in our data.

Statistical Analysis: All statistical analyses were performed by using SPSS statistical software (version 13.0, SPSS Inc., Chicago, III, USA). Categorical variables were described as frequency rates and percentages, and quantitative variables were described using mean (SD) or median (interquartile range) values. The $\chi 2$ test and Fisher exact test were used for categorical variables. Quantitative variables were analyzed by independent sample t test; otherwise, the Mann-Whitney U test was used.

For logistic regression analysis, quantitative variables (Age, Lymphocyte count, C-Reactive Protein, ferritin....) was transformed into categorical variable. The chosen cutoff value is based on the median or interquartile range giving the best OR. Then a univariate logistic regression analysis was performed to identify the clinical, laboratory and CT features associated with Severe/Critical COVID19 pneumonia cases. $\mathrm{P}$ values less than 0.05 were considered as statistically significant.

\section{RESULTS}

Since the first case of SARS-COV2 infection was registered in Oujda in April 2020 and until the end of December, more than 2000 patients were treated at the AL FARABI sub-hospital.

This study was conducted from $01 / 09 / 2020$ to $25 / 12 / 2020$ in the A wing of this center with 567 patients recorded. Mean age was $59.54 \pm 15.5$ years. The sex ratio M/F was 0.87 . Among comorbidities, $35.7 \%$ had diabetes and $23.3 \%$ had hypertension. Symptoms were present in $83.4 \%$ of cases and the mean time to symptom onset was $8.82 \pm$ 3.98 days before hospital admission. The main clinical symptoms were fever in $51.3 \% \%$ of patients, cough in $49.9 \% \%$ and dyspnea in $38.6 \%$.

All patients underwent chest CT scans. Evolution was favorable in $89.5 \%$ of cases, with $9 \%$ in the intensive care unit (Figure 2). The mortality rate for all patients was $2.9 \%$, rising to $4.5 \%$ in the severe/severe group. We did not observe any deaths in patients who were more than $90 \%$ saturated.

Tableau 1: Clinical, laboratory, and radiographic findings of patients on admission

\begin{tabular}{|c|c|}
\hline Caracteristics & Valeurs $(\mathrm{N}=567)$ \\
\hline Age (years) $^{\dagger}$ & $59.54 \pm 15.5$ \\
\hline Male/ Female ${ }^{\S}$ & $\begin{array}{l}263(46.5) / 303 \\
(53.4)\end{array}$ \\
\hline \multicolumn{2}{|l|}{ Comorbidity : } \\
\hline Diabetes ${ }^{\S}$ & $199(35.7)$ \\
\hline Hypertension ${ }^{\S}$ & $130(23.3)$ \\
\hline Heart disease ${ }^{\S}$ & $39(7)$ \\
\hline Asthma $^{\S}$ & $17(3)$ \\
\hline Silicosis ${ }^{\S}$ & $10(1.8)$ \\
\hline $\mathrm{COPD}^{\S}$ & $2(0.4)$ \\
\hline pregnancy ${ }^{\S}$ : & $8(1.4)$ \\
\hline Hemodialysis ${ }^{\S}$ & $32(5.7)$ \\
\hline Cancer ${ }^{\S}$ & $12(2.4)$ \\
\hline Dysthyroidism $^{\S}$ & $12(2.4)$ \\
\hline Gout $^{\S}$ & $6(1.2)$ \\
\hline Trisomy 21 & $2(0.4)$ \\
\hline \multicolumn{2}{|l|}{ Symptoms : } \\
\hline Dyspnea $^{\S}$ & $219(38.6)$ \\
\hline Fever $^{\S}$ & $291(51.3)$ \\
\hline Cough $^{\S}$ & $283(49.9)$ \\
\hline Fatigue $^{\S}$ & $214(37.7)$ \\
\hline Myalgia ${ }^{\S}$ & $146(25.7)$ \\
\hline Anosmia ${ }^{\S}$ & $111(19.6)$ \\
\hline Ageusia $^{\S}$ & $65(11.5)$ \\
\hline Diarrhea $^{\S}$ & $103(18.2)$ \\
\hline Headache ${ }^{\S}$ & $78(13.7)$ \\
\hline \multicolumn{2}{|l|}{ Biological parameters : } \\
\hline White blood cell count $/ \mathrm{L}^{\mathbb{T}}$ & $7000(5100-9300)$ \\
\hline Lymphocyte count /ml II & $1100(800-1700)$ \\
\hline Platelets count, $\times 10^{3} / \mathrm{L}^{\dagger}$ & $240(185-316.25)$ \\
\hline C-Reactive Protein, mg/L ${ }^{\mathbb{I I}}$ & $71(15.8-162)$ \\
\hline Lactate dehydrogenase $\mathrm{U} / \mathrm{L}^{\pi}$ & $555.5(423-753.25$ \\
\hline Creatine kinase U/L & $96(64.5-173.5)$ \\
\hline AST U/L ${ }^{\pi}$ & $32(22-47)$ \\
\hline ALT U/L ${ }^{\mathbb{I}}$ & $28(19-46)$ \\
\hline D-dimers mcg/ml II & $0.8(0.27-479.71)$ \\
\hline Troponin ng/ml ${ }^{\mathbb{I I}}$ & $7(3.32-19.42)$ \\
\hline Ferritin mcg/L ${ }^{\mathbb{I}}$ & $765.04(386.12-1391)$ \\
\hline $\begin{array}{l}\text { Abnormalities in chest CT images } \\
(\%)\end{array}$ & $40(25-55)$ \\
\hline
\end{tabular}

In this study, age, presence of diabetes and/or hypertension were statistically different with a $\mathrm{P}$ value $<0.01$ between groups (Severe/Critical group vs mild/moderate group). Dyspnea as a respiratory symptom was significantly more frequent in severe forms. Table 2 shows a comparison of the two groups by history and symptoms. 
Table 2: Characteristics of differential counts in different severity groups of COVID-19.

\begin{tabular}{|c|c|c|c|c|}
\hline Caracteristics & $\begin{array}{l}\text { Total } \\
(\mathrm{N}=567)\end{array}$ & $\begin{array}{l}\text { Severe/Critical Group } \\
n=294\end{array}$ & $\begin{array}{l}\text { Mild/Moderate group } \\
\mathrm{n}=\mathbf{2 7 3}\end{array}$ & $P$ value \\
\hline $\begin{array}{l}\text { Age (years) }{ }^{\dagger} \\
\text { Gender }{ }^{\S}\end{array}$ & $59.54 \pm 15.5$ & $63,28 \pm 12,4$ & $55,13 \pm 17.2$ & $<0.01 * *$ \\
\hline $\begin{array}{l}\text { Male } \\
\text { Female }\end{array}$ & $\begin{array}{l}263(46.5) \\
303(53.4)\end{array}$ & $\begin{array}{l}147(55,9) \\
145(48,5)\end{array}$ & $\begin{array}{l}116(44.1) \\
154(51,5)\end{array}$ & 0.091 \\
\hline Diabetes ${ }^{\S}$ & $199(35.7)$ & $119(60.4)$ & $78(39,6)$ & 0.003 \\
\hline Hypertension $\S$ & $130(23.3)$ & $82(63.6)$ & $47(36.4)$ & 0.002 \\
\hline Heart disease ${ }^{\S}$ & $39(7)$ & $22(56.4)$ & $17(43.6)$ & 0.62 \\
\hline Asthma ${ }^{\S}$ & $16(3)$ & $7(43.8)$ & $9(56.2)$ & 0.61 \\
\hline Silicosis $^{\S}$ & $10(1.8)$ & $6(60)$ & $4(40)$ & 0.75 \\
\hline Hemodialysis ${ }^{\S}$ & $32(5.7)$ & $21(65.6)$ & $11(34.4)$ & 0.14 \\
\hline Dyspnea $^{\S}$ & $219(38.6)$ & $156(71.2)$ & $63(28.8)$ & $<0.01 * *$ \\
\hline Fever ${ }^{\S}$ & $291(51.3)$ & $179(61.5)$ & $112(38.5)$ & $<0.01 * *$ \\
\hline Cough ${ }^{\S}$ & 283 (49.9) & $130(45.9)$ & $153(54.1)$ & $<0.01 * *$ \\
\hline Fatigue $^{\S}$ & $214(37.7)$ & $74(34.6)$ & $140(65.4)$ & 0.9 \\
\hline Myalgia ${ }^{\S}$ & $146(25.7)$ & $65(44.5)$ & $81(55.5)$ & 0.067 \\
\hline Anosmia ${ }^{\S}$ & $111(19.6)$ & $20(18.1)$ & $91(81.9)$ & $0.012 *$ \\
\hline Ageusia $^{\S}$ & $65(11.5)$ & $16(24.6)$ & $49(75.4)$ & 0.22 \\
\hline Diarrhea ${ }^{\S}$ & $103(18.2)$ & $39(37.8)$ & $64(62.1)$ & 0.85 \\
\hline Headache $^{\S}$ & $78(13.7)$ & $30(38.5)$ & $48(61.5)$ & 0.64 \\
\hline
\end{tabular}

${ }^{\dagger}$ Mean \pm standard deviation, ${ }^{\S}$ Number (percent \%)

The biological examination, albeit limited, available at our center would be informative about the evolution of the disease, as there was a statistically significant difference with a $P$ value $<0.01$ for most biological parameters (Table
3). The extent of lung lesions on CT scan was also statistically significant.

Univariate analysis of our sample identified several parameters that reflect the severity of hypoxia, such as age and lymphocyte count. Table 4 details the results obtained.

Table 3: Characteristics of differential laboratory and imaging counts in different severity groups of COVID-19.

\begin{tabular}{|c|c|c|c|c|}
\hline Caracteristics & $\begin{array}{c}\text { Total } \\
(\mathrm{N}=567)\end{array}$ & $\begin{array}{c}\text { Severe/Critical Group } \\
n=294\end{array}$ & $\begin{array}{c}\text { Mild/Moderate Group } \\
n=273\end{array}$ & $P$ value \\
\hline White blood cell count / $\mathrm{L}^{\mathbb{T}}$ & $7000(5100-9300)$ & $8200(6000-10300)$ & $6100(4800-8295)$ & $<0.01 * *$ \\
\hline Lymphocyte count $/ \mathrm{ml}^{\mathbb{T l}}$ & $1100(800-1700)$ & $900(600-1200)$ & $1600(1085-2100)$ & $<0.01 * *$ \\
\hline C-Reactive Protein, mg/L II & $71(15.8-162)$ & $125.2(61.75-195)$ & $21(9-93.75)$ & $<0.01 * *$ \\
\hline Lactate dehydrogenase U/L ${ }^{\llbracket}$ & $555.5(423-753.25$ & $601.5(474.75-867)$ & $460.5(385.75-621.5)$ & $<0.01 * *$ \\
\hline Creatine kinase U/L & $96(64.5-173.5)$ & $104(66-209)$ & $89(63-143.75)$ & 0.034 \\
\hline ALT U/L ${ }^{\pi}$ & $28(19-46)$ & $32(22.75-50)$ & $25(16-43)$ & $<0.01 * *$ \\
\hline D-dimer mcg/ml II & $1.08(0.27-479.71)$ & $4(0.3-805)$ & $1(0.25-20.25)$ & 0.16 \\
\hline Troponin $\mathrm{ng} / \mathrm{ml}^{\mathrm{I}}$ & $7(3.32-19.42)$ & $7(3.4-20)$ & $8.15(2.22-17.5)$ & 0.57 \\
\hline Ferritin ng/ml ${ }^{\mathrm{q}}$ & $765.04(386.12-1391)$ & $921.13(456-1676.49)$ & $406(226.23-865.9)$ & $<0.01 * *$ \\
\hline $\begin{array}{l}\text { Abnormalities in chest CT } \\
\text { images }(\%)\end{array}$ & $40(25-55)$ & $45(30-60)$ & $25(10-40)$ & $<0.01 * *$ \\
\hline
\end{tabular}

${ }^{\dagger}$ Mean \pm standard deviation, ${ }^{\S}$ number (percent), ${ }^{\text {Il }}$ Median (interquartile range)

\section{DISCUSSION}

Coronavirus 2019 (covid-19) is considered as a multisystemic disease, but it manifests mainly as respiratory symptoms, which determines the prognosis. Although in most patients the symptoms are mild and the prognosis is good, covid-19 can develop into a severe disease with pneumonia, acute respiratory distress syndrome, and even multiorgan failure. (6;7).

This cohort studied risk factors related to severe/critical forms of SARS-COV2 infection. Advanced age is a risk factor with a mean of $63,28 \pm 12.4$ years in severe forms, and this parameter appears consistently in the literature as a risk factor for mortality; $80 \%$ of deaths due to COVID are observed in patients $\geq 65$ years old $(8 ; 9)$. The same observation has been made in patients infected with severe acute respiratory syndrome (SARS) or middle east respiratory syndrome (MERS) $(10 ; 11)$.

Like Wang D. et al (12), There was no difference in the sex ratio (men/women) between the two groups, indicating that gender was not a risk factor for disease severity.
However other studies, reported that male sex has been associated with COVID-19 severity and mortality $(13 ; 14)$. This severity is due to the higher prevalence of comorbidities in men, such as smoking and its effects on respiratory function, and cardiovascular pathology (15). In fact, the prevalence of comorbidities is associated with severe forms of COVID-19, especially in patients with cardiovascular pathology and metabolic disorders (16). More than one third of our patients are diabetic and $23.3 \%$ are hypertensive. These comorbidities influence disease severity, with an OR of 1.85 for hypertension (OR 1.85, 95\% CI: $1.23-2.77, \mathrm{P} 0.003$ ) and 1.67 for diabetes (OR 1.67, 95\%CI: 1.18-2.38, P 0.004). Xiaochen Li et al (16) found that only hypertension was associated with severe forms. The presence of diabetes was associated with more severe forms of acute respiratory distress syndrome, which is likely to be related to immune deficiency. (17)

Patients with underlying respiratory disease accounted for $5.2 \%$ of our sample and we observed only one death in this group. 
Tableau 4: Univariate Logistic Analysis of clinical, laboratory and imaging Features for Severe/Critical COVID-19 Pneumonia.

\begin{tabular}{|c|c|c|c|}
\hline \multirow[t]{2}{*}{ Variables } & \multicolumn{3}{|c|}{ Univariate analysis } \\
\hline & OR & CI $95 \%$ & P value \\
\hline Age (years) $>60$ & 2.35 & $1.67-3.31$ & $<0.01$ \\
\hline Male & 1.36 & $0.98-1.89$ & 0.067 \\
\hline Diabetes & 1.85 & $1.23-2.77$ & 0.003 \\
\hline Hypertension & 1.67 & $1.18-2.38$ & 0.004 \\
\hline Dypnea & 8.57 & $3.72-19.75$ & $<0.01$ \\
\hline Fever & 3.21 & $1.5-6.85$ & $<0.01$ \\
\hline Leukocyte count $\geq 10000 / \mathrm{L}$ & 3.76 & $2.3-6.15$ & $<0.01$ \\
\hline Lymphocyte count $<1300 / \mathrm{ml}$ & 6.26 & $4.25-9.23$ & $<0.01$ \\
\hline C-Reactive Protein $>70 \mathrm{mg} / \mathrm{L}$ & 5.7 & $3.84-8.48$ & $<0.01$ \\
\hline Lactate dehydrogenase $>400 \mathrm{U} / \mathrm{L}$ & 2.58 & $1.36-4.91$ & 0.004 \\
\hline Creatine kinase $>200 \mathrm{U} / \mathrm{L}$ & 2.16 & $1.32-3.53$ & 0.002 \\
\hline $\mathrm{AST}>25 \mathrm{U} / \mathrm{L}$ & 2.17 & $1.47-3.22$ & $<0.01$ \\
\hline $\mathrm{ALT}>25 \mathrm{U} / \mathrm{L}$ & 2.15 & $1.48-3.11$ & $<0.01$ \\
\hline D-dimer mcg/ml & 1 & $0.99-1$ & 0.33 \\
\hline Troponin $\mathrm{ng} / \mathrm{ml}$ & 1 & 1 & 0.78 \\
\hline Ferritin $>500 \mathrm{ng} / \mathrm{ml}$ & 3.6 & $1.64-7.89$ & $<0.01$ \\
\hline Extent of lung lesions on CT $(\%)$ & 1.052 & $1.03-1.068$ & $<0.01$ \\
\hline
\end{tabular}

OR: Odds Ratio, IC: 95\%confidence interval, AST: Aspartate aminotransferase.

ALT: Alanine aminotransferase. CT: Compute Tomography

In the univariate analysis of symptoms, dyspnea (OR: 8.57 CI95\%: 3.72-19.75 P<0.01) and fever (OR: 3.21 CI95\%: 1.5-6.85 P 0.003) were predictors of hypoxia. In a metaanalysis by Z. Zheng (19), dyspnea (OR: 4.16, 95\%CI 3.1$5.53, \mathrm{P}<0.001)$ was associated with severe form and mortality, while fever (OR: $0.56,95 \%$ CI $0.38-0.82, \mathrm{P}$ $0.003)$ was a protective factor.

Several biomarkers reflecting the inflammatory response reflect disease severity. There is a need for an inexpensive and readily available biomarker to detect the potential severe forms at an early stage (20).

In the univariate analysis, hypoxia was associated with lymphopenia (OR: 6.26 CI95\%: 4.25-9.23). Lymphocyte depletion in severe/critical patients suggests that a large number of immune cells are depleted and immune function is suppressed (21)._Lymphopenia may result from three mechanisms: virus-induced apoptosis, increased lymphocyte activation and inhibition of lymphocyte proliferation $(22,23,24)$. Lymphopenia is an important component of severe COVID-19 and may be useful in predicting the severity of clinical outcome.

Elevated levels of leukocytes, CRP, ALT and ferritinemia may be associated with viral invasion-induced cytokine overload and may co-exist with other types of infection, as repported by recent studies (25).

Studies reveal that the haematological profile changes during SARS-COV2 infection, neutrophils participate early in the immune defense after severe pneumonia and become cytotoxic by granulation and lysis (26). Thus, studies suggest that neutrophil recruitment may exacerbate COVID-19 immunopathology (27). The increase in leukocyte count is significantly correlated with disease severity (28). In our study, we found the same result.

Positive CRP is significantly correlated with the extent of lung injury and disease severity (29). This has been shown and used for early diagnosis of infectious pneumonia (30). AST/ALT (OR 2.17/2.15) is increased in the severe/critical group and may be due to viral invasion of the liver or hypoxia or cytokine-induced liver injury (31). Hyperferritinemia is significantly associated with an increased risk of progression to severe forms of COVID19 (32), mirroring what has been previously reported on the prognostic role of this protein in other inflammatory conditions (33).

Other parameters such as elevated $\mathrm{LDH}>245 \mathrm{U} / \mathrm{L}$, creatinine $>133 \mathrm{~mol} / \mathrm{L}$, procacitonin $>0.5 \mathrm{ng} / \mathrm{ml}$ have also been associated with the severity of this infection (34). Ddimer levels $>1 \mu \mathrm{g} / \mathrm{L}$ indicate blood hypercoagulability; it is a strong predictor of mortality (35); thrombogenesis and risk of visceral embolisation (36).

The extent of lung lesions on computed tomography is associated with clinical severity (OR 1.052; 95\% CI 1.03$1.068 ; \mathrm{P} 0.005)$; in addition to this parameter, some studies have analysed the type of lesion on computed tomography; consolidation was significantly more frequent in severe/critical patients, indicating that alveoli are completely congested with inflammatory exudate. This usually means that the virus spreads to the airway epithelium, resulting in necrotizing bronchitis and diffuse alveolar damage. $(37,38)$.

\section{CONCLUSION}

Being part of a third world country, our health care structure is equipped with a limited technical platform that requires streamlining of tests to improve the effectiveness of care. In fact, many of the factors we use are related to disease severity, which can help clinicians to assess patient severity and evaluate prognosis.

Our study has some limitations related to its retrospective nature on the one hand and on the other hand the patients might be at different stages of disease at admission. In addition, the different definitions of disease severity used in COVID-19 might be another limitation.

In addition, the importance of biological parameters in COVID assessment has been demonstrated, sensitivity and specificity limits should be established for each parameter.

\section{AUTHORS' CONTRIBUTIONS}

The participation of each author corresponds to the criteria of authorship and contributorship emphasized in the Recommendations for the Conduct, Reporting, Editing, and Publication of Scholarly work in Medical Journals of the International Committee of Medical Journal Editors. Indeed, all the authors have actively participated in the redaction, the revision of the manuscript and provided approval for this final revised version.

\section{COMPETING INTERESTS}

The authors declare no competing interests. 


\section{REFERENCES}

[1] El Zowalaty ME, Järhult JD. From SARS to COVID-19: A previously unknown SARSrelated coronavirus (SARS-CoV-2) of pandemic potential infecting humans - Call for a One Health approach. One health (Amsterdam, Netherlands) 2020;9:100124.

[2] Gorbalenya A.E., Baker S.C., Baric R.S. (sous presse); BioRxiv: 2020. Severe acute respiratory syndrome-related coronavirus: the species and its viruses - a statement of the coronavirus study group. [Google Scholar]

[3] Dae-Gyun A., Hye-Jin S., Mi-Hwa K. Current status of epidemiology, diagnosis, therapeutics, and Vaccines for Novel Coronavirus Disease 2019 (COVID-19) J. Microbiol. Biotechnol. 2020;30(3):313-324. [PubMed] [Google Scholar]

[4] Njenga, M. K., Dawa, J., Nanyingi, M., Gachohi, J., Ngere, I., Letko, M., Otieno, C. F., Gunn, B. M., \& Osoro, E. (2020). Why is There Low Morbidity and Mortality of COVID-19 in Africa?, The American Journal of Tropical Medicine and Hygiene, 103(2), 564-569. Retrieved May 27, 2021, from https://www.ajtmh.org/view/journals/tpmd/103/2/ar ticle-p564.xml

[5] National Health Commission. Chinese Clinical Guidance For COVID-19 Pneumonia Diagnosis and Treatment- American College of Cardiology (acc.org) (7th version).

[6] ChenN, ZhouM,DongX, et al. Epidemiological and clinical characteristics of 99 cases of 2019 novel coronavirus pneumonia inWuhan, China: a descriptive study. Lancet. 2020;395:507-513.

[7] Chung M, Bernheim A, Mei X, et al. CT imaging features of 2019 novel coronavirus (2019-nCoV). Radiology. 2020;295:202-207.

[8] Zhou F, Yu T, Du R, Fan G, Liu Y, Liu Z, et al. Clinical course and risk factors for mortality of adult inpatients with COVID-19 in Wuhan, China: a retrospective cohort study. Lancet 2020;395:105462. doi:10.1016/S0140- 6736(20)30566-3.

[9] To KK-W, Tsang OT-Y, Leung W-S, Tam AR, Wu T-C, Lung DC, et al. Temporal profiles of viral load in posterior oropharyngeal saliva samples and serum antibody responses during infection by SARS-CoV2: an observational cohort study. Lancet Infect Dis 2020. doi:10.1016/s1473-3099(20)30196-1.

[10] Hong KH, Choi JP, Hong SH, Lee J, Kwon JS, Kim $\mathrm{SM}$, et al. Predictors of mortality in Middle East respiratory syndrome (MERS). Thorax 2018;73:286- 9. doi:10.1136/thoraxjnl-2016209313

[11] Choi KW, Chau TN, Tsang O, Tso E, Chiu MC, Tong WL, et al. Outcomes and Prognostic Factors in 267 Patients with Severe Acute Respiratory Syndrome in Hong Kong. Ann Intern Med 2003;139. doi:10.7326/0003-4819-139-9-

[12] Wang D, Hu B, Hu C, et al. Clinical characteristics of 138 hospitalized patients with 2019 novel coronavirus-infected pneumonia inWuhan, China. JAMA. 2020.

[13] The Lancet. The gendered dimensions of COVID19. Lancet 2020;395:1168. doi:10.1016/S01406736(20)30823-0.

[14] Cai H. Sex difference and smoking predisposition in patients with COVID-19. Lancet Respir Med 2020;8:e20. doi:10.1016/S2213-2600(20)30117-X.
[15] Zheng Q-L, Duan T, Jin L-P. Single-cell RNA expression profiling of ACE2 and AXL in the human maternal-Fetal interface. Reprod Dev Med 2020;4:7. doi:10.4103/2096-2924.278679.

[16] Xiaochen Li, Shuyun Xu, Muqing Yu, Ke Wang, Yu Tao, Ying Zhou, et al. Risk factors for severity and mortality in adult COVID-19 inpatients in Wuhan J ALLERGY CLIN IMMUNOL 2020; 146: 1. doi.org/10.1016/j.jaci.2020.04.006

[17] McGurnaghan, S. J., Weir, A., Bishop, J., Kennedy, S., Blackbourn, L. A. K., McAllister, et al. (2021). Risks of and risk factors for COVID-19 disease in people with diabetes: a cohort study of the total population of Scotland. The Lancet Diabetes \& Endocrinology, 9(2), 82-93.

[18] Li B, Yang J, Zhao F, Zhi L, Wang X, Liu L, et al. Prevalence and impact of cardiovascular metabolic diseases on COVID-19 in China. Clin Res Cardiol 2020. doi:10.1007/s00392-020-01626-9.

[19] Zhao Q, Meng M, Kumar R, Wu Y, Huang J, Deng Y, Weng Z, Yang L. Lymphopenia is associated with severe coronavirus disease 2019 (COVID-19) infections: A systemic review and meta-analysis. Int J Infect Dis. 2020 Jul;96:131-135. doi: 10.1016/j.ijid.2020.04.086. Epub 2020 May 4. PMID: 32376308; PMCID: PMC7196544.

[20] Li, K., Wu, J., Wu, F., Guo, D., Chen, L., Fang, Z., \& Li, C. (2020). The Clinical and Chest CT Features Associated With Severe and Critical COVID-19 Pneumonia. Investigative radiology, 55(6), 327331.

[21] Henry BM, De Oliveira MHS, Benoit S, Plebani M, Lippi G. Hematologic, biochemical and immune biomarker abnormalities associated with severe illness and mortality in coronavirus disease 2019 (COVID-19): a meta-analysis. Clin Chem Lab Med. 2020 Apr 10;58: 1021-8.

[22] Lippi G, Plebani M. Laboratory abnormalities in patients with COVID-2019 infection. Clin Chem Lab Med. 2020 Mar 3;58:1131-4.

[23] Terpos E, Ntanasis-Stathopoulos I, Elalamy I, Kastritis E, Sergentanis TN, PolitouM, et al. Hematological findings and complications of COVID-19. American Journal of Hematology [Internet]. $\mathrm{n} / \mathrm{a}(\mathrm{n} / \mathrm{a}) . \quad$ Available from: https://doi.org/10.1002/ajh.25829

[24] Zhaohai Zheng a , b , 1 , Fang Peng a , 1 , Buyun Xu a , Jingjing Zhao a , b , Huahua Liu c, Jiahao Peng d, et al. Risk factors of critical \& mortal COVID-19 cases: A systematic literature review and metaanalysis. Journal of Infection 81 (2020) e16-e25.

[25] Haick AK, Rzepka JP, Brandon E, Balemba OB, Miura TA. Neutrophils are needed for an effective immune response against pulmonary rat coronavirus infection, but also contribute to pathology. J Gen Virol https://doi.org/10.1099/vir.0.061986-0.

[26] Didangelos A. COVID-19 hyperinflammation: what about neutrophils? mSphere 2020;5(3). https://doi.org/10.1128/mSphere.00367-20.

[27] Aditya A, Prakash KJ, Abhishek K.Differential white blood cell count in the COVID-19 : A crosssectional study of 148 patients.Diabetes and metabolic syndrome : clinical research and reviews 14 (2020) 2020-2102. 
[28] Matsumoto H, Kasai T, Sato A, Ishiwata S, Yatsu $\mathrm{S}$, Shitara J, et al. Associa- tion between C-reactive protein levels at hospital admission and long-term mortality in patients with acute decompensated heart failure. Heart Vessels 2019;34(12):1961-8, http://dx.doi.org/10.1007/s00380-019-01435-9.

[29] Chalmers S, Khawaja A, Wieruszewski PM, Gajic O, Odeyemi Y. Diagnosis and treatment of acute pulmonary inflammation in critically ill patients: the role of inflammatory biomarkers. World J Crit Care Med 2019;8(5):59-71, http://dx.doi.org/10.5492/wjccm.v8.i5.59.

[30] Yeo C, Kaushal S, Yeo D. Enteric involvement of coronaviruses: is faecal-oral transmission of SARSCoV-2 possible?. Lancet Gastroenterol Hepatol. 2020;5:335-7.

[31] Thirumalaisamy P Velavan, Christian G Meyer. Mild Versus severe COVID-19 : Laboratory markers. International Journal of Infectious Diseases. 95(2020) 304-307.
[32] Ruscitti P, Berardicurti O, Di Benedetto P et al. Severe COVID-19, another piece in the puzzle of the hyperferritinemic syndrome. An immunomodulatory perspective to alleviate the storm. Front Immunol $2020 ; 11: 1130$.

[33] Huang C, Wang Y, Li X, et al. Clinical features of patients infected with 2019 novel coronavirus in Wuhan, China.[J]. Lancet 2020; 395 (10223):497506. doi: 10. 1016/s0140-6736(20)30183-5 .

[34] Zhou F, Yu T, Du R, et al. Clinical course and risk factors for mortality of adult inpatients with COVID19 in Wuhan. China: a retrospective cohort study. Lancet 2020 Mar 28;395(10229):1054-1062.

[35] Koo HJ, Lim S, Choe J, et al. Radiographic and CT features of viral pneumonia. Radiographics. 2018;38:719-739.

[36] Franquet T. Imaging of pulmonary viral pneumonia. Radiology. 2011;260:18-39. 